\title{
Green synthesis of a new AI-MOF based on the aliphatic linker mesaconic acid: structure, properties and in-situ crystallisation studies of Al-MIL-68-Mes
}

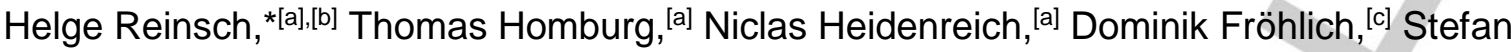 \\ Hennninger, ${ }^{[c]}$ Michael Wark ${ }^{[\mathrm{d}]}$ and Norbert Stock*[a]
}

\begin{abstract}
A new aluminium MOF based on the short aliphatic linker molecule mesaconic acid $\left(\mathrm{H}_{2}\right.$ Mes; methylfumaric acid) is reported. Al-MIL-68-Mes with composition $\left[\mathrm{Al}(\mathrm{OH})\left(\mathrm{O}_{2} \mathrm{C}-\mathrm{C}_{3} \mathrm{H}_{4}-\mathrm{CO}_{2}\right)\right] \cdot n \mathrm{H}_{2} \mathrm{O}$ is obtained after short reaction times of 45 minutes under mild, aqueous synthesis conditions $\left(95^{\circ} \mathrm{C}\right)$. It exhibits a kagome-like framework structure with large hexagonal and small trigonal channels (diameters of $\sim 6$ and $\sim 2 \AA$, respectively) and a specific surface area of $\mathrm{S}_{\mathrm{BET}} \approx 1040 \mathrm{~m}^{2} / \mathrm{g}\left(\mathrm{V}_{\mathrm{MIC}}=0.42 \mathrm{~cm}^{3} / \mathrm{g}\right)$. A sigmoidal vapour sorption isotherm for water and uptakes of water and methanol above $30 \mathrm{wt} \%$ were observed. Al-MIL-68-Mes is stable against water ad-/desorption and its thermal stability is $350^{\circ} \mathrm{C}$ in air. The proton conductivity for the hydrated MOF showed values up to $1.1^{*} 10^{-5} \mathrm{~S} / \mathrm{cm}$ at $130^{\circ} \mathrm{C}$ and $100 \%$ relative humidity, which exceeds the values observed for the non-hydrated compound by up to four orders of magnitude. Using synchrotron radiation we also studied the crystallisation of the MOF by in-situ PXRD at temperatures from 80 to $100{ }^{\circ} \mathrm{C}$. Kinetic evaluation revealed that the induction periods and crystallization times vary depending on the synthesis batch but the rate limiting steps are consistently observed.
\end{abstract}

\section{Introduction}

During the recent two decades there has been a steadily increasing interest in the class of porous materials designated as metal-organic frameworks (MOFs). ${ }^{1}$ Such compounds are obtained by assembling organic and inorganic building units into porous framework structures in which the respective building blocks can be theoretically replaced by topologically equivalent analogues. ${ }^{2}$ Due to their porous nature, MOFs are often discussed to be used in fields of application such as catalysis, ${ }^{3}$ separation, ${ }^{4}$ sensing, ${ }^{5}$ gas storage ${ }^{6}$ or heat transformation. ${ }^{7}$ The most intensely studied sub-class of MOFs is based on polycarboxylates and as a general tendency it has been be observed that such compounds exhibit higher stability when tri-

[a] Dr. H. Reinsch, T. Homburg, N. Heidenreich, Prof. Dr. N. Stock Institut für Anorganische Chemie der CAU Kiel

Max-Eyth-Straße 2, 24118 Kiel, Germany

E-mail: stock@ac.uni-kiel.de

[b] Dr. H. Reinsch,

MOF Apps AS, c/o Smidig Regnskapsservice ANS, P. Box 24

Tåsen, 0801 Oslo, Norway

[c] Dr. D. Fröhlich, Dr. S. K. Henninger

Fraunhofer Institute for Solar Energy Systems ISE

Heidenhofstrasse 2, 79110 Freiburg, Germany

[d] Prof. Dr. M. Wark

Institut für Chemie, Carl von Ossietzky Universität Oldenburg

Carl-von-Ossietzky-Strasse 9-11, 26129 Oldenburg, Germany,

Supporting information for this article is given via a link at the end of the document. and tetravalent metal ions are implemented as inorganic building unit. ${ }^{8}$ Hence the industrial interest is focussed on such highvalent cations. ${ }^{9}$ Especially MOFs based on aluminium ions are of interest ${ }^{10}$ since the reactants are inexpensive and easily available and the diverse known frameworks often show remarkable stability under industrially relevant conditions, for example as adsorbents in heat-transformation experiments. ${ }^{11}$

The Al-MOF denoted as aluminium fumarate or MIL-53-Fum has attracted serious commercial interest due to its stability ${ }^{12}$ and its facile and benign synthesis. ${ }^{13}$ The crystal structure of this MOF with composition $\left[\mathrm{Al}(\mathrm{OH})\left(\mathrm{O}_{2} \mathrm{C}-\mathrm{C}_{2} \mathrm{H}_{2}-\mathrm{CO}_{2}\right)\right]$ adopts the well-known topology of MIL-53 ${ }^{14}$ but unlike its analogues based on terephthalate ${ }^{15}$ it does not exhibit strong framework flexibility also called "breathing" - under ambient conditions. The inorganic building units are infinite chains of trans-corner sharing $\mathrm{AlO}_{6}$ polyhedra which are connected via fumarate molecules to form a porous framework with rectangular channels. Its water sorption behaviour makes it an interesting candidate for implementation in heat-exchange devices ${ }^{16}$ and its stability could allow for $\mathrm{CO}_{2}$ capture ${ }^{17}$ while it is also suitable for fluoride removal by a decomposing mechanism. ${ }^{18}$ Aluminium fumarate is also able to separate hydrocarbons via shape selectivity ${ }^{19}$ and since it exhibits breathing only under very high pressure, it can be also used for the storage of mechanical energy. ${ }^{20}$

We have been interested for a long time in MOFs based on $\mathrm{Al}^{3+}$ ions due to their outstanding properties $21,22,23$ and their magnificent structural features. ${ }^{24,25,26}$ Therefore we decided to evaluate whether a functionalisation of Al-MIL-53-Fum is possible. Thus methylfumaric acid, also known as mesaconic acid $\left(\mathrm{H}_{2} \mathrm{Mes}\right)$, was investigated as linker molecule. This compound has hardly been used in the synthesis of MOFs although it is commercially available. It is known to form a $\mathrm{Zr}$ MOF $^{27,28}$ with a framework structure similar to the one of zirconium fumarate. ${ }^{29}$ Moreover a zinc mesaconate is known which is obtained using itaconic acid (methylenesuccinic acid). ${ }^{30}$ This linker is isomerised in-situ to mesaconic acid and in a similar reaction, a one-dimensional lead mesaconate coordination polymer was obtained when itaconic acid was employed (Fig. 1). ${ }^{31}$

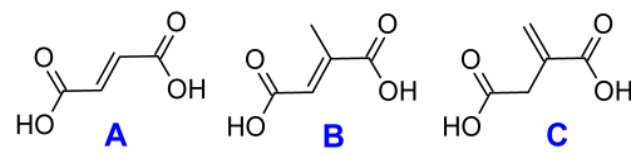

Figure 1. The dicarboxylic acids discussed in the text. From left to right: fumaric acid $(\mathbf{A})$, mesaconic acid $(\mathbf{B})$ and the isomeric itaconic acid $(\mathbf{C})$.

An analogue of MOF-5 incorporating mesaconic acid was also reported. ${ }^{32}$ Despite this scarce use in MOF chemistry mesaconic 
acid can be considered a promising organic building block for the green synthesis of MOFs, ${ }^{33}$ especially since a biosynthetic pathway for its production from glutamate in water was already described. ${ }^{34}$

Herein we report the synthesis and properties of the new mesaconate based Al-MOF Al-MIL-68-Mes with the composition $[\mathrm{Al}(\mathrm{OH})(\mathrm{Mes})] \cdot n \mathrm{H}_{2} \mathrm{O}$. The compound was thoroughly characterized by means of powder X-ray diffraction, IR spectroscopy, thermogravimery and regarding its sorption properties towards $\mathrm{N}_{2}, \mathrm{CO}_{2}$, water and methanol vapour. Moreover its proton conductivity under humid conditions was investigated by means of electrical impedance spectroscopy. The crystallization of Al-MIL-68-Mes was studied by in-situ PXRD using synchrotron radiation, kinetically analyzed and compared to the formation behavior of Al-MIL-53-Fum.

\section{Results and Discussion}

\section{Synthesis and crystal structure}

The well-known Al-MIL-53-Fum was originally obtained using the toxic and teratogenic $\mathrm{N}, \mathrm{N}$ '-dimethylformamide as solvent. ${ }^{35}$ Such chemicals pose a major drawback for synthesis at large scale and subsequently a much milder and environmentally more benign route has been developed. ${ }^{13}$ This green preparative route utilizes a solution of sodium fumarate and a solution of $\mathrm{Al}_{2}\left(\mathrm{SO}_{4}\right)_{3} \cdot 18 \mathrm{H}_{2} \mathrm{O}$ which are combined at $60{ }^{\circ} \mathrm{C}$ under stirring. After several minutes at this temperature Al-MIL-53-Fum can be isolated by filtration. Al-MIL-68-Mes can be obtained in a similar manner by dissolving mesaconic acid and $\mathrm{NaOH}$ in water and adding a solution of $\mathrm{Al}_{2}\left(\mathrm{SO}_{4}\right)_{3} \cdot 18 \mathrm{H}_{2} \mathrm{O}$ (ratio $\mathrm{Al}^{3+}$ :linker: $\mathrm{NaOH}$ $1: 1: 3,\left[\mathrm{Al}^{3+}\right]$ and $\left[\mathrm{H}_{2} \mathrm{Mes}\right] 0.15 \mathrm{M}$ each). This immediately leads to the precipitation of an X-ray amorphous solid. The crystalline AlMIL-68-Mes is obtained after subsequently heating the mixture in a microwave oven under stirring at $95^{\circ} \mathrm{C}$ for $45 \mathrm{~min}$. The applied microwave heating is not necessarily facilely implemented into a prospective up-scaling of the synthesis. However, since the reaction can be also carried out under conventional dielectric heating (see section on in-situ experiments), we anticipate that multigram amounts of AI-MIL68-Mes can be easily obtained. Since the MOF is obtained as a microcrystalline powder its structure was determined from PXRD data (for details see experimental section). The final Rietveld plot is shown in Figure 2 and some relevant parameters are shown in Table 1. The structure of Al-MIL-68-Mes is formed by the interconnection of chains of trans-corner sharing $\mathrm{AlO}_{6}$ polyhedra (in which $\mathrm{OH}$ groups act as $\mu$-connecting ligands) via mesaconate linker molecules in four directions. Hence small trigonal channels and large hexagonal channels are formed which exhibit diameters of approximately 2 and $6 \AA$, respectively (measured based on Van der Waals radii and omitting protons). The formation of the kagome-like MIL-68 framework is quite remarkable. When approximately linear dicarboxylates are employed for the synthesis of Al-MOFs, in most cases a framework with MIL-53 structure and composition $\left[\mathrm{Al}(\mathrm{OH})\right.$ (linker)] is obtained. ${ }^{36,37,38,39}$

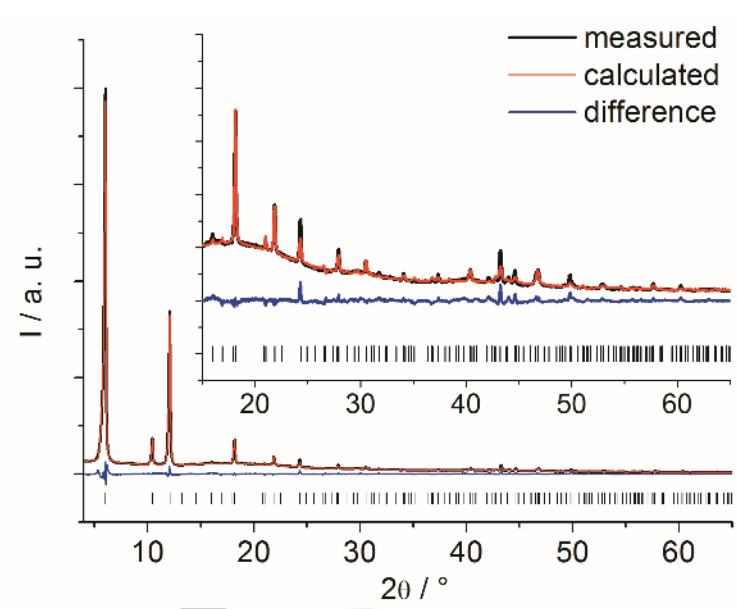

Figure 2. Rietveld plot for AI-MIL-68-Mes. The black line is the measured data, the red line gives the calculated data and the blue line is the difference curve. Vertical bars indicate the peak positions.

Table 1. Crystallographic parameters for Al-MIL-68-Mes as obtained from Rietveld refinement.

\begin{tabular}{cc}
\hline Formula & {$\left[\mathrm{Al}(\mathrm{OH})\left(\mathrm{O}_{2} \mathrm{C}-\mathrm{C}_{3} \mathrm{H}_{4}-\mathrm{CO}_{2}\right)\right] \cdot \mathrm{H}_{2} \mathrm{O}$} \\
Crystal System & trigonal \\
Space Group & $P-3$ \\
$a=b[\AA]$ & $16.8912(7)$ \\
$c[\AA]$ & $6.669(2)$ \\
$\alpha=\beta\left[^{\circ}\right]$ & 90 \\
$\gamma\left[^{\circ}\right]$ & 120 \\
$\mathrm{R}_{W P}, \mathrm{R}_{\text {Exp }}, \mathrm{R}_{\mathrm{Bragg}}[\%]$ & $5.5,3.5,2.1$ \\
$\mathrm{GoF}$ & 1.58 \\
\hline
\end{tabular}

Only few examples describe the synthesis of other framework topologies like the mesoporous $\mathrm{MIL}-101$ framework with approximate composition $\left[\mathrm{Al}_{3}(\mathrm{O})(\mathrm{OH})\left(\mathrm{H}_{2} \mathrm{O}\right)_{2}(\text { linker })_{3}\right]^{40}$ and even fewer reports deal with the synthesis of an AI-MOF with MIL-68 structure and composition $\left[\mathrm{Al}(\mathrm{OH})(\right.$ linker) $] \cdot{ }^{41}$ It is even more surprising that only by adding a $\mathrm{CH}_{3}$-group to the linker molecules - in comparison with fumaric acid - a different framework topology is observed. We assume that this originates from the different conformations of the linker molecules. In AlMIL-53-Fum, the carboxylate groups are arranged in-plane with the central C-C double bond and hence the MIL-53 framework is preferentially formed. In Al-MIL-68-Mes, the carboxylate groups are arranged perpendicular to the double bond, probably induced by the steric repulsion of the $\mathrm{CH}_{3}$-group, and the MIL-68 framework is obtained (Fig. 3). To further corroborate this observation and assignment, additional solid-state NMR experiments would be very useful. 


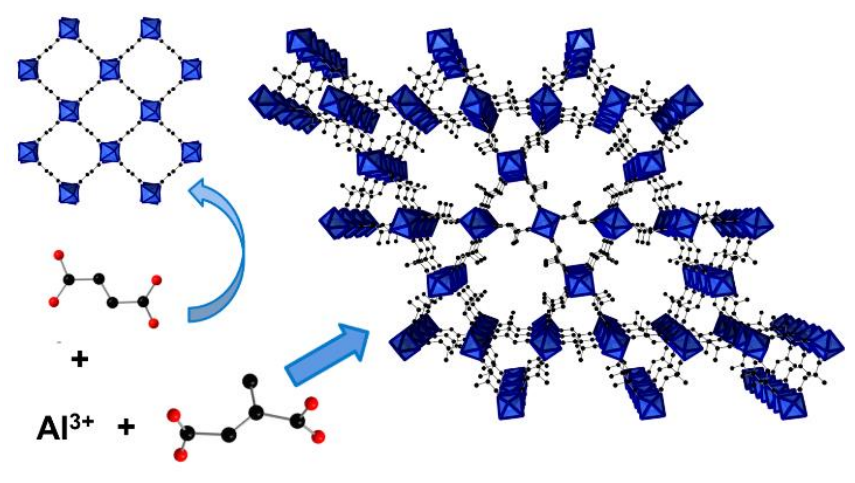

Figure 3. Framework structures and linker conformations for AI-MIL-53-Fum and fumarate (top left) and Al-MIL-68-Mes and mesaconate (bottom left and right).

\section{Properties of Al-MIL-68-Mes}

Al-MIL-68-Mes possesses similar porosity towards $\mathrm{N}_{2}$ as Al-MIL53-Fum (Fig. 4, top). The isotherm measured at $-196{ }^{\circ} \mathrm{C}$ exhibits a typical Type I shape, indicating a microporous material. The apparent specific surface area amounts to $S_{B E T} \approx 1040 \mathrm{~m}^{2} / \mathrm{g}$ and the micropore volume as determined at $p / p_{0}=0.5$ is $0.42 \mathrm{~cm}^{3} / \mathrm{g}$. The latter is in excellent agreement with the expected value of $0.425 \mathrm{~cm}^{3} / \mathrm{g}$, calculated for a nitrogen probe molecule with kinetic diameter of $3.6 \AA$ and a structural model bearing protons generated using Material Studio. ${ }^{42}$ These values are also similar to the ones observed for Al-MIL-53-Fum (maximum $\mathrm{S}_{\mathrm{BET}}=1080$ $\left.\mathrm{m}^{2} / \mathrm{g}\right){ }^{14}$ The sorption behaviour towards water and methanol vapour was also investigated (Fig. 4, bottom). The water vapor isotherm shows a sigmoidal shape without pronounced hysteresis and with a steep increase in uptake around $p / p_{0}$ of $\approx$ 0.5 (from $60 \mathrm{mg} / \mathrm{g}$ at $\mathrm{p} / \mathrm{p}_{0}=0.45$ to $340 \mathrm{mg} / \mathrm{g}$ at $\mathrm{p} / \mathrm{p}_{0}=0.55$ ) and a maximum capacity of $374 \mathrm{mg} / \mathrm{g}$ at $\mathrm{p} / \mathrm{p}_{0}=0.9$, which indicates a similar capacity as for other water stable MOFs like AI-MIL-53Fum $(450 \mathrm{mg} / \mathrm{g})^{12}$ or CAU- $10-\mathrm{H}(340 \mathrm{mg} / \mathrm{g}) .{ }^{43}$ Very often MOFs decompose upon water ad-/desorption and thus the remaining porosity after water vapor sorption on AI-MIL-68-Mes was evaluated by nitrogen sorption measurement. Remarkably, the nitrogen isotherms measured prior and after water sorption are virtually identical (see SI, Fig. S3). However, while MOFs are often discussed as adsorbents in heat-pumps using water as fluid ${ }^{7,44}$ the position of the sigmoidal uptake around $p / p_{0}=0.5$ is actually at a too high partial pressure to be efficiently employed in such devices. ${ }^{45}$ Another currently discussed potential field of application for stable MOFs is water harvesting from comparably dry air. ${ }^{46}$ Again, the comparably low affinity of Al-MIL-68-Mes towards water vapor would not suggest that it is a suitable material for this controversially discussed application. ${ }^{47}$ Alcohols like methanol and ethanol are also discussed as fluids in heatexchangers ${ }^{48}$ and therefore we also measured methanol vapor isotherms at $25^{\circ} \mathrm{C}$. The shape of the isotherm changes from sigmoidal to a moderately steep but linear uptake below $\mathrm{p} / \mathrm{p}_{0}=$ 0.4 . The absolute capacity at this partial pressure is $28 \mathrm{wt} \%$ and the absolute capacity at $p / p_{0}=0.9$ is 37 wt $\%$ which is lower than the uptake measured for $\left[\mathrm{Cu}_{3}\left(\mathrm{C}_{9} \mathrm{H}_{3} \mathrm{O}_{6}\right)\left(\mathrm{H}_{2} \mathrm{O}\right)_{3}\right](50 \text { wt\% })^{49}$ which is, however, not stable towards water. No hysteresis can be observed upon desorption. Hence the use of a less hydrophilic fluid leads to a clear shift of the adsorption towards lower partial pressure while preserving the gravimetric capacity. This indicates a comparably hydrophobic framework. Additional data on $\mathrm{CO}_{2}$ adsorption can be found in the $\mathrm{SI}$ (Fig. S4). For $\mathrm{CO}_{2}, \mathrm{Al}-$ MIL-68-Mes shows a virtually linear isotherm with a maximum uptake at $25^{\circ} \mathrm{C}$ and 1 bar of $43.4 \mathrm{mg} / \mathrm{g}$.
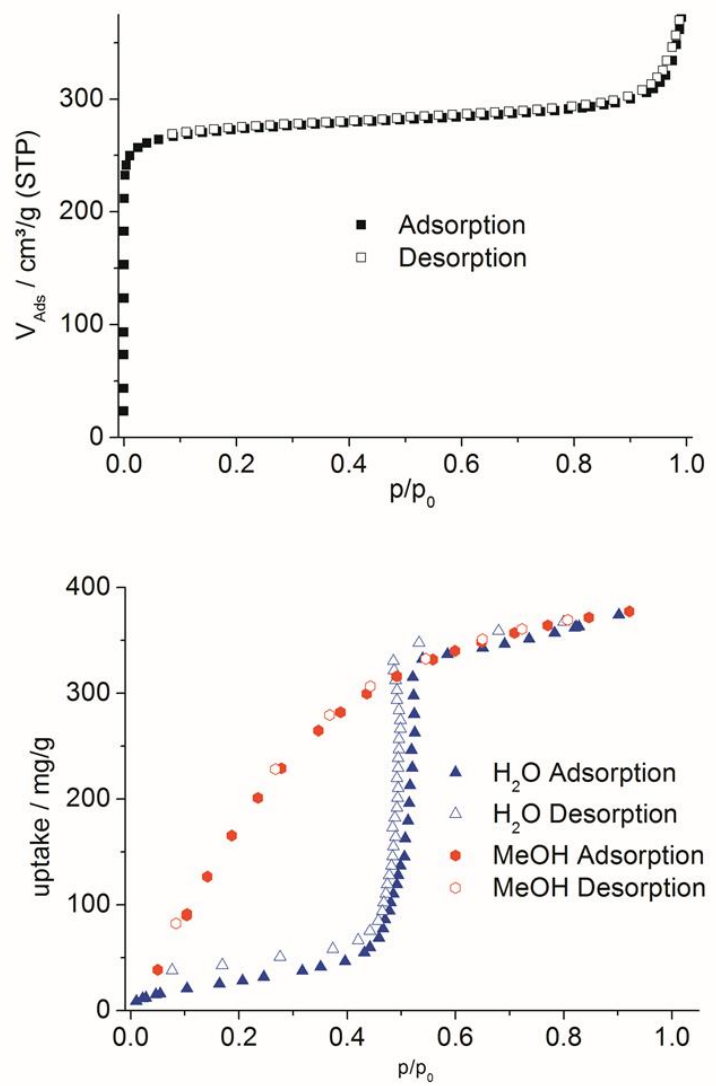

Figure 4. Sorption isotherms of Al-MIL-68-Mes measured using $\mathrm{N}_{2}$ at $-196^{\circ} \mathrm{C}$ (top, black squares), $\mathrm{H}_{2} \mathrm{O}$ at $25^{\circ} \mathrm{C}$ (bottom, blue triangles) and methano (bottom, red circles). Filled symbols represent the adsorption, open symbols the desorption branch.

MOFs that can withstand high relative humidity are also potential candidates for the incorporation into proton conducting devices. ${ }^{50}$ In addition there have been suggestions that water mediated proton conduction in MOFs can be enhanced by hydrophobic subunits like methyl-groups in the framework channels. ${ }^{51}$ Hence the proton conductivity of Al-MIL-68-Mes was investigated by means of electrochemical impedance spectroscopy (EIS). A sample of the MOF was placed between two graphitic slices, placed in a Teflon sample holder between stainless steel electrodes and pressed with an angular moment of $30 \mathrm{cNm}$ to obtain pellets (thickness between 0.7 and $1.0 \mathrm{~mm}$ ). The impedance was measured at controlled relative humidity (50 or $100 \%$, respectively) at different temperatures between 80 
and $130^{\circ} \mathrm{C}$ (see experimental section and SI, Figs. S5, S6 for details). ${ }^{52}$ At a lower relative humidity of $50 \%$ the MOF only exhibits very low proton conductivity with a maximum of $6^{*} 10^{-9}$ $\mathrm{S} / \mathrm{cm}$ at $110^{\circ} \mathrm{C}$. We attribute this to the fact that hardly any water is adsorbed into the pores under these conditions and the conductivity results mostly from water adsorbed on the external particle surface. However, at higher relative humidity (100\%) the pores are filled with adsorbate and the conductivity increases by several orders of magnitude, resulting in values between $9.9^{*} 10^{-7}$ (at $80{ }^{\circ} \mathrm{C}$ ) and $1.1^{*} 10^{-5} \mathrm{~S} / \mathrm{cm}$ (at $130{ }^{\circ} \mathrm{C}$ ) as depicted in figure 5 . The activation energies calculated for the temperature ranges 80 to $110{ }^{\circ} \mathrm{C}$ and 110 to $130^{\circ} \mathrm{C}$ at $100 \%$ relative humidity are approximately $0.15 \mathrm{eV}$ and $0.45 \mathrm{eV}$, indicating a Grotthuss mechanism for proton conduction. ${ }^{53}$ The different regimes for the activation energy can be attributed to the measurement temperature exceeding the boiling point of water. Thus above $100{ }^{\circ} \mathrm{C}$ the properties of the adsorbed species could differ from the properties below this temperature. After the EIS experiment the sample pellet was crushed and characterized by PXRD. The pattern showed no decomposition of the MOF and thus indicates stability under the employed experimental conditions (see SI, Fig. S7).

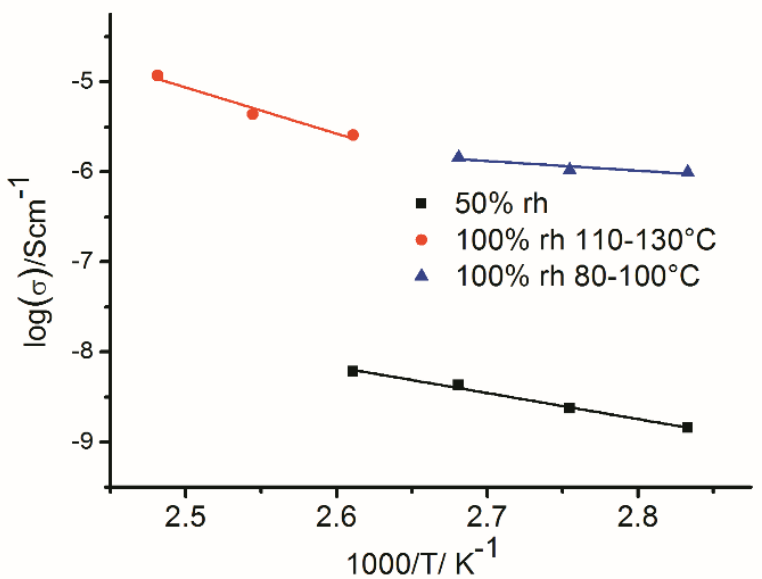

Figure 5. Arrhenius plots for the proton conductivity of Al-MIL-68-Mes at $50 \%$ and $100 \%$ relative humidity depending on the temperature.

Hence, the absolute conductivity values of Al-MIL-68-Mes are orders of magnitude lower compared to other state of the art MOFs, metal phosphates or polymers. ${ }^{54}$ Nevertheless the results underline the stability of the MOF and illustrate very well the correlation between sorption properties and proton conductivity. We also investigated the thermal stability of Al-MIL-68-Mes by means of thermogravimetry (see SI, Fig. S2) and temperature dependent PXRD (Fig. 6, Fig. S8 in the SI for a top view representation), the latter being measured in a capillary under air. The data indicates that the relative intensities change substantially upon removal of the solvent molecules from the pores, which takes place above $100^{\circ} \mathrm{C}$ under the spatially confined conditions in a capillary. The evaporation of the solvent from the pores is thus delayed compared to the thermogravimetric experiment (solvent removal above $50^{\circ} \mathrm{C}$ ). Similarly the decomposition temperature in the TG experiment is lower $\left(350^{\circ} \mathrm{C}\right)$ than in the temperature dependent PXRD measurement $\left(400^{\circ} \mathrm{C}\right)$ which is due to the limited accessibility of the capillary and the slower heating in the thermo-balance. The observed weight losses in the TG experiment for solvent removal (10.3 wt\%) and framework combustion (60.5 wt\%) are in reasonable agreement with the expected values (9.6 wt\% weight loss for removal of $1 \mathrm{H}_{2} \mathrm{O}$ per formula unit and 64.5 wt\% weight loss for framework combustion).

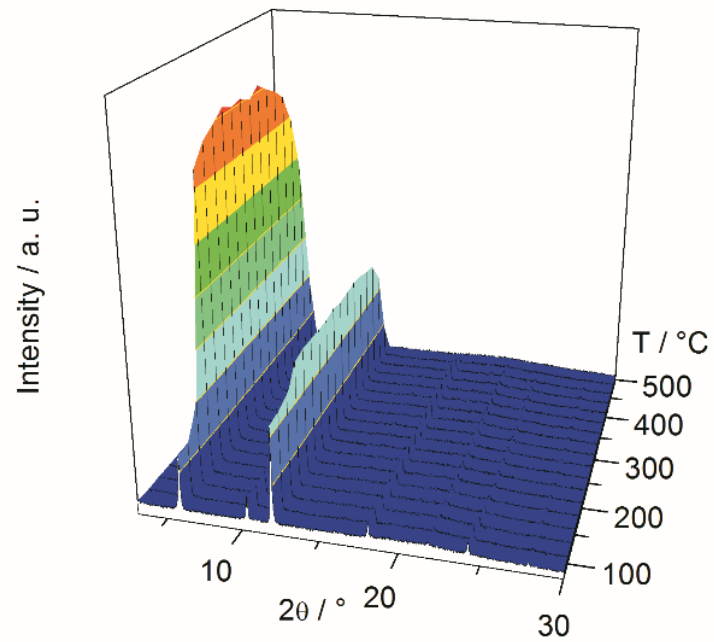

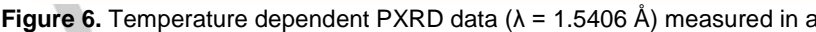
capillary under air.

\section{In-situ diffraction experiments during crystallization}

The formation of Al-MIL-68-Mes proceeds via an X-ray amorphous precipitate that forms immediately upon combining the reactant solutions. In order to elucidate how this affects the formation of the MOF, in-situ PXRD experiments using synchrotron radiation were carried out during the reaction, and the obtained data were kinetically evaluated. Such measurements have been shown to be a useful tool to investigate the formation of MOFs 55 as well as other compound ${ }^{56}$ and to detect crystalline intermediates which can be hardly observed otherwise. ${ }^{57}$ The used set-up is described in more detail elsewhere ${ }^{58}$ and consists mainly of a Pyrex glass tube equipped with magnetic stirrer and devices for accurate heating and cooling of the reaction mixture. This reaction chamber is placed inside the beam path of monochromated synchrotron light and the PXRD data is collected as a function of time using a 2D detector. A typical time dependent 3D plot as observed for an experiment at $90^{\circ} \mathrm{C}$ is shown in Fig. 7. These experiments were carried out at $80^{\circ} \mathrm{C}, 90^{\circ} \mathrm{C}$ and $100^{\circ} \mathrm{C}$. Two different batches of slurry were investigated since such in-situ experiments are most often carried out on homogeneous systems like solutions or gels, and the precipitation of the X-ray amorphous intermediate upon mixing of the reactants was speculated to affect the reproducibility of the experiment. 


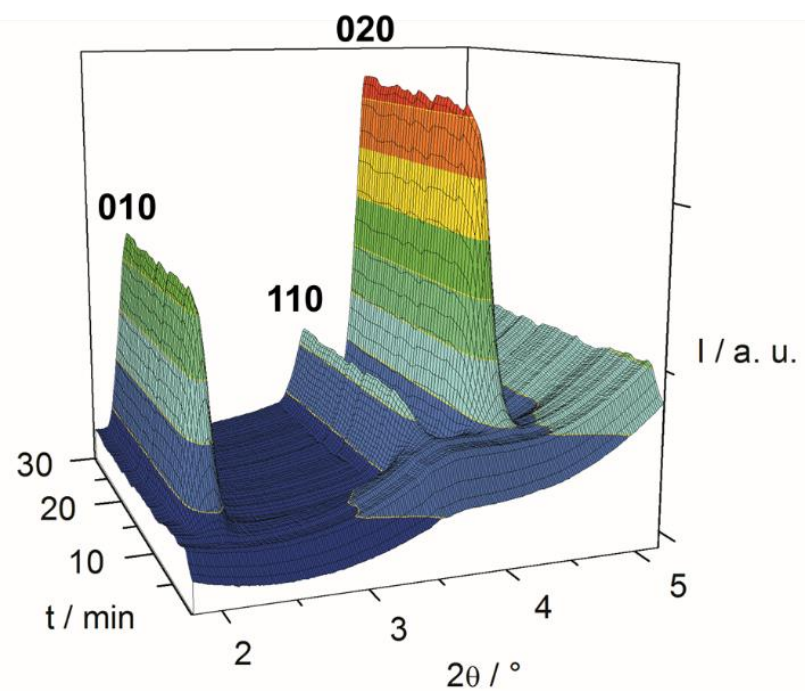

Figure 7. 3D plot for the time dependent crystallisation experiment at $90^{\circ} \mathrm{C}$, measured with a wavelength of $0.53906 \AA$ and a temporal resolution of $30 \mathrm{~s}$. Peaks are marked with the respective Miller indices.

As seen in Figure 7 the relative intensities of the product peaks are similar to the ones of a solvent loaded framework, in contrast to the pattern of the virtually solvent-free framework used for Rietveld refinement (Fig. 1) for which the 010 reflection shows the highest intensity. Thus the 020 reflection is the strongest product peak observed in-situ. It is also obvious that the crystallization of Al-MIL-68-Mes proceeds rapidly after an initial induction period (Fig. S9). The normalized integrated intensity of the 020 reflection was considered proportional to the amount of product formed and thus used to monitor the reaction progress $\alpha$ over time and depending on the reaction temperature (Fig. 8 shows the curves for batch 1 ).

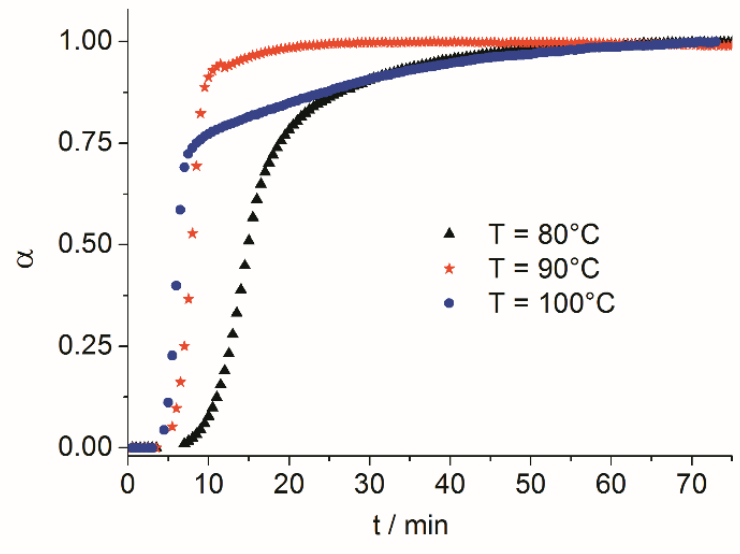

Figure 8. Reaction progress $\alpha$ for the formation of Al-MIL-68-Mes from batch 1 at different temperatures. The normalized integrated intensity of the 020 peak was considered proportional to the amount of product.

From these experiments we could deduce that the induction time for crystallization varies only between 3 minutes at $100{ }^{\circ} \mathrm{C}$ and 6 minutes at $80^{\circ} \mathrm{C}$ and thus is only slightly affected by the temperature (see also Tab. 2). The shape of the curve is apparently differing substantially, depending on the synthesis temperature, and this impression already allows anticipating that temperature increase does not only simply accelerate the reaction as one could expect.

To analyze this observation we employed the Sharp-Hancock plot (Fig. 9, SI Figs. S10-S12) ${ }^{59}$ based on the theories of Avrami $^{60}$ (the approach of Gualtieri ${ }^{61}$ to analyze kinetic data did not allow for a reasonable fitting of the experimental curves). This method of plotting $\ln (-\ln (1-\alpha))$ over $\ln \left(t-t_{0}\right)$ should result in an approximately linear correlation during a certain period of reaction time, at least in case a constant reaction mechanism dominates the crystallization during this period. The slope of a linear regression gives the so called Avrami exponent $n$ which is indicative of the slowest reaction step and thus the most probable reaction mechanism. The intercept equals $n \cdot \ln (k)$ and thus gives a pseudo rate constant for the crystallization. We have to mention that this method of data interpretation is actually restricted to the crystallization from homogenous systems like solutions or gels. Especially the occurrence of the X-ray amorphous by-product could limit the validity of the employed theories. However, based on the observations for Fe-MIL-89 $\left[\mathrm{Fe}_{3} \mathrm{O}\left(\mathrm{CH}_{3} \mathrm{OH}\right)_{3}\left[\mathrm{O}_{2} \mathrm{C}-(\mathrm{CH})_{4}-\mathrm{CO}_{2}\right]_{3} \mathrm{Cl}\right],{ }^{62}$ and MOF-74 ${ }^{63}$ which form from intermediates via re-dissolution and crystallization, a similar mechanism seems to be likely in our case. Nevertheless, this kinetic analysis was predominantly carried out to evaluate if and to which extent it can be applied to such slurry based systems at all.

For the crystallization of Al-MIL-68-Mes from slurry batch 1 we observed more than one distinguishable linear region in the Sharp-Hancock plots at all temperatures (Fig. 9). Therefore two linear regressions were carried out for the reactions at 80 and $90{ }^{\circ} \mathrm{C}$, covering an initial and a later reaction stage. At $100{ }^{\circ} \mathrm{C}$ three different stages of the reaction were deduced from the Sharp-Hancock plot. Hence, three different Avrami exponents and rate constants were determined, respectively.

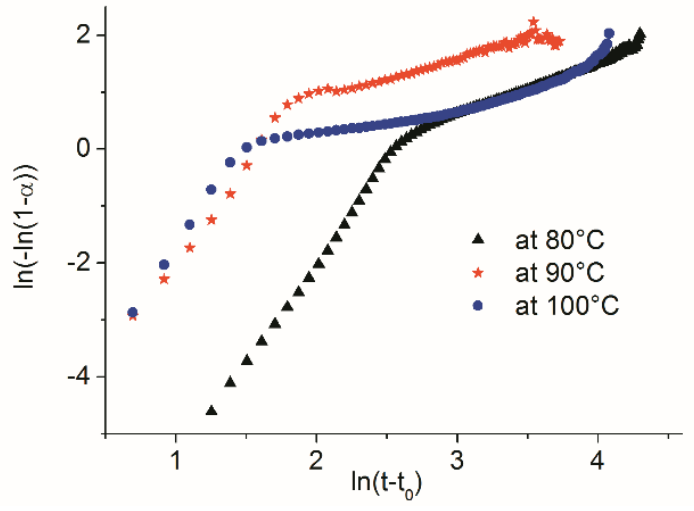

Figure 9. Sharp-Hancock plots for the crystallisation of Al-MIL-68-Mes from batch 1 for the different temperatures. At 80 and $90^{\circ} \mathrm{C}$, two different linear regions can be observed while three different regions are visible for the reaction at $100{ }^{\circ} \mathrm{C}$. See also linear regressions in the supporting information.

The evaluated values are summarized in Table 2. During the initial reaction period the Avrami exponents are consistently 
between 3.46 and 3.67 , indicating that nucleation is the rate limiting step (exponents typically between 2 and $4{ }^{64}$ ). The formation is accelerated at higher temperatures during the initial reaction stage, as indicated by the pseudo rate constants which are increasing from $0.077 \mathrm{~min}^{-1}$ at $80^{\circ} \mathrm{C}$ to $0.231 \mathrm{~min}^{-1}$ at $100^{\circ} \mathrm{C}$. The length of this time period depends on the synthesis temperature and decreases from $13 \mathrm{~min}$ at $80^{\circ} \mathrm{C}$ to $4 \mathrm{~min}$ at $100{ }^{\circ} \mathrm{C}$. Thus during the starting period the crystallization proceeds in a consistent manner. When the reaction mechanism changes the reactions have already proceeded to values for a between 0.65 and 0.82 .

During the respective second stage, the Avrami exponents are $0.949(8)$ and $0.63(2)$ at 80 and $90{ }^{\circ} \mathrm{C}$, respectively, ranging between diffusion limited reaction (typically $\mathrm{n}<0.7$ ) and first order reactions (typically $n \approx 1$ ). At $100^{\circ} \mathrm{C}$ this second and thus in this case intermediate stage has an Avrami exponent of only $0.352(6)$ and is therefore also considered limited by diffusion, while an Avrami exponent of 0.85(1) is observed during the third stage. The pseudo rate constants are indicative of a substantially accelerated crystallization at $90^{\circ} \mathrm{C}$ (increase of $\mathrm{k}$ from $0.0925 \mathrm{~min}^{-1}$ at $80^{\circ} \mathrm{C}$ to 0.592 at $\left.90^{\circ} \mathrm{C}\right)$. At $100^{\circ} \mathrm{C}$ the value for $\mathrm{k}$ decreases compared to the reaction at $90^{\circ} \mathrm{C}(0.300$ during the second stage and 0.100 during the last stage).

Table 2. Parameters deduced from the in-situ PXRD data for slurry batch 1.

\begin{tabular}{|c|c|c|c|}
\hline Reaction Temperature & $80^{\circ} \mathrm{C}$ & $90^{\circ} \mathrm{C}$ & $100^{\circ} \mathrm{C}$ \\
\hline Induction time & $6 \mathrm{~min}$ & $3.5 \mathrm{~min}$ & $3 \mathrm{~min}$ \\
\hline $\begin{array}{l}\text { Reaction time ( } \alpha=1 \\
\text { after) }\end{array}$ & $77.5 \mathrm{~min}$ & $40.5 \mathrm{~min}$ & $62.5 \mathrm{~min}$ \\
\hline initial Avrami Exponent & $3.57(4)$ & $3.46(9)$ & $3.67(10)$ \\
\hline initial k $\left[\mathrm{min}^{-1}\right)$ & 0.077 & 0.206 & 0.231 \\
\hline $\begin{array}{l}\text { change after } \mathrm{t}-\mathrm{t}_{0}= \\
\text { at } \alpha=\end{array}$ & $\begin{array}{l}13 \min \\
0.65\end{array}$ & $\begin{array}{l}5.5 \min \\
0.82\end{array}$ & $\begin{array}{l}1^{\text {st }}: 4 \mathrm{~min} ; 0.68 \\
2^{\text {nd: }}: 22 \mathrm{~min} ; 0.86\end{array}$ \\
\hline later Avrami Exponent & $0.949(8)$ & $0.63(2)$ & $\begin{array}{l}1^{\text {st }}: 0.352(6) \\
2^{\text {nd: }}: 0.850(12)\end{array}$ \\
\hline later $\mathrm{k}\left[\mathrm{min}^{-1}\right)$ & 0.0925 & 0.592 & $1^{\text {st: }} 0.300$ \\
\hline
\end{tabular}

This unexpected, decelerated crystallization at $100{ }^{\circ} \mathrm{C}$ is reproducibly observed for a second experiment at $100{ }^{\circ} \mathrm{C}$ using slurry batch 1 (Fig. S13). The curves for the reaction progress are not perfectly overlapping but nevertheless similar and the evaluated kinetic parameters are consistent with the ones evaluated in the first experiment (Fig. S14, Avrami exponents of $3.41,0.32$ and 0.85 with rate constants of $0.269,0.441$ and $0.097 \mathrm{~min}^{-1}$ at 80,90 and $100{ }^{\circ} \mathrm{C}$ ). In summary this means that the overall reaction is accelerated at $90^{\circ} \mathrm{C}$ compared to $80^{\circ} \mathrm{C}$ but it is decelerated at $100^{\circ} \mathrm{C}$ compared to $90^{\circ} \mathrm{C}$ and thus a higher reaction temperature does not speed up synthesis in the case of Al-MIL-68-Mes.

However, using a different slurry batch this slow-down of crystallization is not necessarily reproducible. While the composition and preparation of this slurry batch 2 was exactly the same, the formation of Al-MIL-68-Mes is not decelerated (Fig. 10). Nevertheless, the same changes for the Avrami exponents are observed in the Sharp-Hancock plots, indicating differing rate limiting steps during the reaction at all temperatures (see SI, Figs S15-S17).

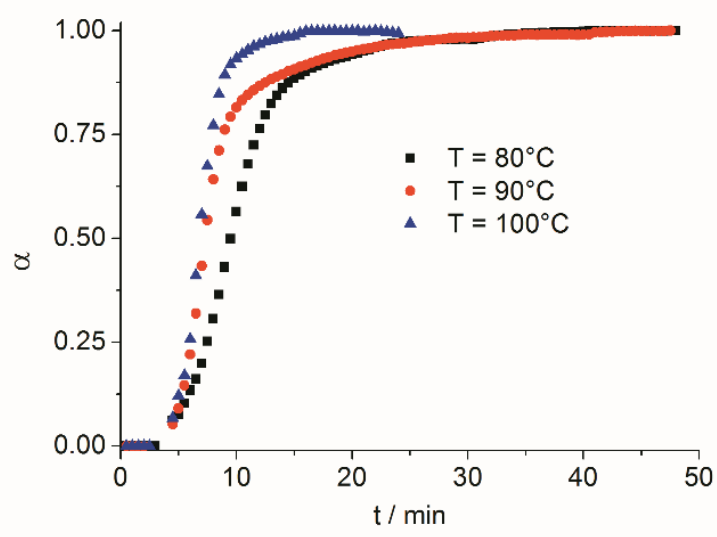

Figure 10. Reaction progress $\alpha$ for the formation of Al-MIL-68-Mes from batch 2 at different temperatures.

Hence the kinetic parameters evaluated from these SharpHancock plots are also differing for batch 2 (Table 3). The induction times hardly differ but the reaction times are drastically varying. However, the values for the Avrami exponents are very similar for the reactions at $80^{\circ} \mathrm{C}$ and $90{ }^{\circ} \mathrm{C}$, and the rate constants are also similar to the ones observed for batch 1 . For the synthesis at $100{ }^{\circ} \mathrm{C}$ from batch 2 , the kinetic parameters during the initial stage are comparable for batch 1 while they differ substantially for the later reaction stage.

Table 3. Parameters deduced from the in-situ PXRD data for slurry batch 2 .

\begin{tabular}{llll}
\hline Reaction Temperature & $80{ }^{\circ} \mathrm{C}$ & $90{ }^{\circ} \mathrm{C}$ & $100{ }^{\circ} \mathrm{C}$ \\
\hline Induction time & $3 \mathrm{~min}$ & $2 \mathrm{~min}$ & $2.5 \mathrm{~min}$ \\
$\begin{array}{l}\text { Reaction time }(\alpha=1 \\
\text { after) }\end{array}$ & $47 \mathrm{~min}$ & $47.5 \mathrm{~min}$ & $18.5 \mathrm{~min}$ \\
initial Avrami Exponent & $3.31(4)$ & $3.30(6)$ & $3.07(8)$ \\
initial $\mathrm{k}\left[\mathrm{min}^{-1}\right)$ & 0.093 & 0.164 & 0.203 \\
mechanism change & $13.5 \mathrm{~min}$ & $7.5 \mathrm{~min}$ & $7 \mathrm{~min} ;$ \\
after $\mathrm{t}-\mathrm{t} 0$ & $\alpha \approx 0.84$ & $\alpha=0.80$ & $\alpha \approx 0.91$ \\
later Avrami Exponent & $1.08(3)$ & $0.64(2)$ & $0.95(1)$ \\
later $\mathrm{k}$ [min $\left.{ }^{-1}\right)$ & 0.129 & 0.313 & 0.378 \\
\hline
\end{tabular}

This surprising finding cannot be unambiguously explained solely from the available data. Nevertheless we propose the following interpretation: The Avrami exponents indicate that the initial crystallization is always limited by nucleation. At this stage 
the reaction should be consuming mostly reactants which are present in solution and have not precipitated. After the consumption of these reactants, the dissolution of the X-ray amorphous intermediate limits the accessible amount of reactants and therefore the Avrami exponents indicate a change in the formation mechanism. Thus the chemical properties and especially the homogeneity of the intermediate solid are probably strongly affecting the formation kinetics during the later reaction stages. However, due to its X-ray amorphous nature and the rapid precipitation upon mixing of the reactants these properties differ from batch to batch. Based on the measured data this can drastically affect the kinetic constants and thus the reaction times, however, the rate limiting step behind the crystallization as indicated by the Avrami exponent remains the same.

For comparison we also investigated the crystallization of AlMIL-53-Fum, which can be obtained simply by using fumaric acid instead of mesaconic acid for the synthesis. Under such conditions no precipitate is formed upon mixing but a viscous gel is obtained. Nevertheless the crystallization starts virtually instantaneously upon reaching the synthesis temperature and is completed after $\approx 3$ minutes (see SI, Fig. S18). Hence the kinetics of formation for AI-MIL-53-Fum and AI-MIL-68-Mes differ substantially while the compounds can be obtained under very similar conditions.

\section{Conclusions}

The title compound AI-MIL-68-Mes was synthesised under sustainable conditions and exhibits a high specific surface area of $1040 \mathrm{~m}^{2} / \mathrm{g}$, accompanied by remarkable thermal $\left(350^{\circ} \mathrm{C}\right)$ and chemical stability (stable upon water vapour sorption). Moreover the EIS experiments illustrate very well how the affinity towards water can affect the proton conductivity. The vapour sorption curves demonstrate clearly the influence of the comparably hydrophobic inner surface unto water and methanol adsorption. The discovery of Al-MIL-68-Mes gives an example for the promising opportunities that are given by green synthesis conditions and the use of sustainable linker molecules for the future. We expect that several, yet unexplored, porous and stable MOFs await their discovery under such reaction conditions. There exist several linker molecules which are derivatives of citric acid, ${ }^{65}$ just like the employed mesaconic acid, which could be utilised for the synthesis of MOFs. Moreover the in-situ experiments indicate that the formation of MOFs is still largely unexplored and future studies will show if the complexity observed for Al-MIL-68 is a singular phenomenon or can be observed rather commonly under similar synthesis conditions.

\section{Experimental Section}

Materials. All used chemicals are commercially available and were employed without further purification.
Methods. The synthesis of Al-MIL-68-Mes was carried out in glass vials $\left(\mathrm{V}_{\mathrm{Max}}=20 \mathrm{~mL}\right)$ equipped with a magnetic stirring bar using a Biotage initiator microwave oven. Powder X-ray diffraction (PXRD) data were collected on a STOE Stadi MP diffractometer equipped with a Mythen detector using monochromated $\mathrm{CuKa}_{1}$ radiation in transmission geometry. All processing of the crystallographic data was done with TOPAS. ${ }^{66}$ IRspectra were measured on a Bruker ALPHA-FT-IR A220/D-01 spectrometer equipped with an ATR-unit. The thermogravimetric analyses were recorded using a NETZSCH STA 429 CD analyzer with a heating rate of $4 \mathrm{~K} \mathrm{~min}^{-1}$ under flowing air (flow rate $75 \mathrm{ml} \mathrm{min}^{-1}$ ). Elemental analysis was measured with a Eurovector EA analyzer. The force field based geometry optimizations were carried out using the Forcite package available in the Materials Studio software based on the implemented Universal Force Field (UFF). ${ }^{42}$ For the electrical impedance spectroscopy measurements, a ZahnerZennium electrochemical workstation was used to determine the proton conductivity over the frequency range of 1 to $10^{6} \mathrm{~Hz}$ and employing an oscillating voltage of $100 \mathrm{mV}$. The in-situ diffraction experiments were measured at beamline P09 at DESY, Hamburg. ${ }^{67}$ The reaction cell was place inside the beam path and the data was recorded using a 2-D XRD 1621 PerkinElmer detector (2048 x 2048 pixel, pixel size $0.2 \times 0.2 \mathrm{~mm}$ ) with a temporal resolution of $30 \mathrm{~s}$. Prior to the experiments the set-up was parametrized using $\mathrm{LaB}_{6}$ as standard (wavelength $0.53906 \AA$, sample-detector distance $820 \mathrm{~mm}$ ). All data conversion of the 2D data was carried out using Fit2D. ${ }^{68}$ Sorption isotherms for $\mathrm{N}_{2}, \mathrm{CO}_{2}$ and $\mathrm{H}_{2} \mathrm{O}$ were measured using a BelSorpMax and methanol adsorption characteristics were obtained by volumetric methods using a Quantachrome AutoSorp instrument.

Electrochemical Impedance Spectroscopy. The powdered samples were incorporated into a stack comprising the sample sandwiched between two graphitic slices. The stack was placed in a PTFE sample holder, where two porous stainless steel electrodes (diameter $8 \mathrm{~mm}$ ) served as working and counter electrode. The sample holder bath was placed in a temperature-controlled custom-made stainless steel chamber and pressed with an angular moment of $30 \mathrm{cNm}$ to obtain pellets (thickness between 0.7 and $1.0 \mathrm{~mm}$ ). Before measuring at different relative humidity values (50\% and $100 \%)$ the samples were equilibrated overnight under the respective conditions. For each series of temperature dependent measurements, the samples were equilibrated for 2-4 hours at the desired temperature before measuring each data point. Every measurement was carried out three times to ensure reproducibility. The proton conductivity (see SI) was obtained by using the Ohmic resistance of the samples determined by EIS.

Synthesis. Al-MIL-68-Mes was synthesized by dissolving $390 \mathrm{mg}$ (3 mmol) mesaconic acid in $15.2 \mathrm{~mL} \mathrm{H}_{2} \mathrm{O}$ and $1.8 \mathrm{~mL}$ freshly prepared aqueous $\mathrm{NaOH}$ solution $(5 \mathrm{M}, 1.8 \mathrm{~mL}, 9 \mathrm{mmol})$ under stirring. A $0.5 \mathrm{M}$ solution of $\mathrm{Al}_{2}\left(\mathrm{SO}_{4}\right)_{3} \cdot 18 \mathrm{H}_{2} \mathrm{O}(3 \mathrm{~mL}, 1.5 \mathrm{mmol}$ corresponding to $3 \mathrm{mmol}$ $\mathrm{Al}^{3+}$ ) was added under vigorous stirring leading to the precipitation of an $X$-ray amorphous solid. This slurry was placed inside the microwave oven and heated for $45 \mathrm{~min}$ at $95^{\circ} \mathrm{C}$ under stirring. The obtained white solid was filtered off and re-dispersed under stirring in $15 \mathrm{~mL} \mathrm{H}_{2} \mathrm{O}$ at ambient conditions for 15-30 min. This washed product was filtered off, rinsed with acetone and dried under ambient conditions. To obtain a nearly guest free framework, the MOF is heated for $30 \mathrm{~min}$ at $90^{\circ} \mathrm{C}$ in a drying oven and quickly prepared for PXRD measurement. Please note that due to the water adsorption properties the intensities in the PXRD pattern can easily change, even depending on the weather. Elemental analysis for $\left[\mathrm{Al}(\mathrm{OH})\left(\mathrm{O}_{2} \mathrm{C}-\mathrm{C}_{3} \mathrm{H}_{4}-\mathrm{CO}_{2}\right)\right] \cdot 1.5 \mathrm{H}_{2} \mathrm{O}$ measured/calculated: $\mathrm{C}$ $30.2 \% / 30.2 \%, \mathrm{H} 2.7 \% / 4 \%$.

In-situ experiments. A large reaction slurry batch of $30 \mathrm{~mL}$ was prepared and constantly stirred to give a homogenous mixture. $3 \mathrm{~mL}$ 
fractions were filled into the Pyrex tube inside the reaction chamber. A large stirring bar $(\approx 15 \times 5 \mathrm{~mm})$ was used to warrant constant agitation and homogeneity of the reaction mixture throughout the experiments. The reactions were carried out at 80,90 and $100{ }^{\circ} \mathrm{C}$. The PXRD data was measured with a temporal resolution of $30 \mathrm{~s}$. To account for beam intensity fluctuations the data was normalized based on the strongest reflection of the heating mantle made of aluminium. The integrals of the reflections being proportional to the reaction progress a were determined using the software F3 tool. ${ }^{69}$

Structure determination. The PXRD pattern could be successfully indexed, suggesting a hexagonal or trigonal cell $(a=b=16.890$ (3) $\AA$ and $c=2.2157(5) \AA$ or a multiple thereof). This symmetry and the intensity distribution let us suspect a similarity to the structure of MIL-68. However, the known crystallographically characterized terephthalates exhibit orthorhombic $C$-centered symmetry ${ }^{70}$ (which is related to the hexagonal symmetry) and thus only an indirect relation was anticipated. Structural models of Al-MIL-68-Mes in a hexagonal/trigonal cell $((a=b=16.890 \AA$ and $c=6.63 \AA$ as the threefold of the indexed value) were thus generated from scratch in several hexagonal or trigonal space groups using Material Studio. Error! Bookmark not defined. However, none of the hexagonal models could be refined by Rietveld methods. The model in the trigonal space group $P-3$ could be eventually refined, taking into account one residual water molecule which was identified by Fourier synthesis. The refinement moreover indicated an ordering of the functional methyl groups which were initially considered only statistically ordered in the starting models.

\section{Acknowledgements}

This project was supported by the German Science Foundation (STO 643/10-1, RE 4057/1-1 and WA 1116/30-1). This work has been also supported by the MATsynCELL project through the Röntgen-Ångström Cluster, supported by the Swedish Research Council and the German Federal Ministry of Education and Research (BMBF). Parts of this research were carried out at the light source PETRA III at DESY, a member of the Helmholtz Association (HGF). We would like to thank Dr. Uta Ruett for assistance in using beamline P09. Thomas Homburg thanks the Deutsche-Bundesstiftung-Umwelt (DBU) for financial support.

Keywords: Metal-organic frameworks - Microporous materials • in-situ diffraction • vapour sorption • aluminium carboxylates 


\section{Entry for the Table of Contents}

\section{FULL PAPER}

\section{Green Aluminium Mesaconate}

The new MOF Al-MIL-68-Mes based on mesaconic acid was obtained under green synthesis conditions and exhibits the rare kagome structure. It shows high porosity and stability under humid conditions. Its formation was followed by in-situ PXRD.

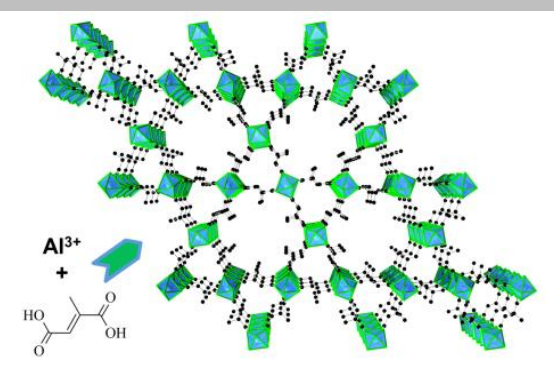

Helge Reinsch, * Thomas Homburg, Niclas Heidenreich, Dominik Fröhlich, Stefan Hennninger, Michael Wark and Norbert Stock*

Page No. - Page No.

Title 
1 a) Special issue Chem. Rev. 2012, 112, 673-1268; b) Themed collections Chem. Soc. Rev. 2014.

2 O. M. Yaghi, M. O'Keeffe, N. W. Ockwig, H. K. Chae, M. Eddaoudi, J. Kim, Nature 2003, 423, 705-714.

${ }^{3}$ P. Valvekens, F. Vermoortele, D. De Vos, Catal. Sci. Tech. 2013, 3, 1435-1445.

${ }^{4}$ B. Van de Voorde, B. Bueken, J. Denayer, D. De Vos, Chem. Soc. Rev. 2014, 43, 5766-5788.

5 I. Stassen, B. Bueken, H. Reinsch, J. F. M. Oudenhoven, D. Wouters, J. Hajek, V. Van Speybroeck, N. Stock, P. M. Vereecken, R. Van Schaijk, D. De Vos, R. Ameloot, Chem. Sci. 2016, 7, 5827-5832.

${ }^{6}$ Y. He, W. Zhou, G. Qian, B. Chen, Chem. Soc. Rev. 2014, 43, 5657-5678.

7 J. Canivet, A. Fateeva, Y. Guo, B. Coasne, D. Farrusseng, Chem. Soc. Rev. 2014, 43, 5594-5617.

${ }^{8}$ T. Devic, C. Serre, Chem. Soc. Rev. 2014, 43, 6097-6115.

${ }^{9}$ M. Gaab, N. Trukhan, S. Maurer, R. Gummaraju, U. Müller, Micropor. Mesopor. Mater. 2012, 157, 131-136.

${ }^{10}$ T. Loiseau, C. Volkringer, M. Haouas, F. Taulelle, G. Férey, Compt. Rend. Chim. 2015, 18, 1350-1369; L.-H. Schilling, H. Reinsch, N. Stock in The Chemistry of Metal-Organic Frameworks: Synthesis, Characterization, and Applications, (Ed.: S. Kaskel), Wiley-VCH, Weinheim, 2016, pp. 105-135.

${ }^{11}$ D. Fröhlich, E. Pantatosaki, P. D. Kolokathis, K. Markey, H. Reinsch, M. Baumgartner, M. A. van der Veen, D. E. De Vos, N. Stock, G. K. Papadopoulos, S. Henninger, C. Janiak, J. Mat. Chem. A 2016, 4, 11859-11869.

${ }^{12}$ F. Jeremias, D. Fröhlich, C. Janiak, S. Henninger, RSC Adv., 2014, 4, 24073-24082.

${ }^{13}$ E. Leung, U. Mueller, N. Trukhan, H. Mattenheimer, G. Cox, S. Blei, US Patent US 8,524,932 B2, 2013.

${ }^{14}$ E. Alvarez, N. Guillou, C. Martineau, B. Bueken, B. Van de Voorde, C. Le Guillouzer, P. Fabry, F. Nouar, F. Taulelle, D. De Vos, J.-S. Chang, K. H. Cho, N. Ramsahye, T. Devic, M. Daturi, G. Maurin and C. Serre, Angew. Chem. Int. Ed. 2015, 54, 3664-3668.

${ }^{15}$ T. Loiseau, C. Serre, C. Huguenard, G. Fink, F. Taulelle, M. Henry, T. Bataille, G. Ferey, Chem.- Eur. J. 2004, 10, 1373-1382.

${ }^{16}$ F. Jeremias, D. Fröhlich, C. Janiak, S. Henninger, RSC Adv, 2014, 38, 1846-1852.

17 J. A. Coelho, A. M. Ribeiro, A. F. P. Ferreira, S. M. P. Lucena, A. E. Rodrigues, D. C. S. de Azevedo, Ind. Eng. Chem. Res. 2016, 55, $2134-2143$.

${ }^{18}$ S. Karmakar, J. Dechnik, C. Janiak, S. De, J. Hazard. Mater. 2016, 303, 10-20.

${ }^{19}$ B. Bozbiyik, J. Lannoeye, D. E. De Vos, G. V. Baron, J. F. M. Denayer, Phys. Chem. Chem. Phys. 2016, 18, 3294-3301.

${ }^{20}$ P. G. Yot, L. Vanduyfhuys, E. Alvarez, J. Rodriguez, J.-P.I Itié, P. Fabry, N. Guillou, T. Devic, I. Beurroies, P. L. Llewellyn, V. Van Speybroeck, C. Serre, G. Maurin, Chem. Sci. 2016, 7, 446-450.

${ }^{21}$ A. Weiss, N. Reimer, N. Stock, M. Tiemann, T. Wagner, Phys. Chem. Chem. Phys. 2015, 17, 21634-21642.

${ }^{22}$ N. Reimer, B. Bueken, S. Leubner, C. Seidler, M. Wark, D. De Vos, N. Stock, Chem. - Eur. J. 2015, 21, 12517-12524.

${ }^{23}$ A. Cadiau, J. Sun Lee, D. Damasceno Borges, P. Fabry, T. Devic, M. T. Wharmby, C. Martineau, D. Foucher, F. Taulelle, C.-H. Jun, Y. K. Hwang, N. Stock, M. F. De Lange, F. Kapteijn, J. Gascon, G. Maurin, J.-S. Chang, C. Serre, Adv. Mater. 2015, 27, 4775-4780.

${ }^{24}$ M. T. Wharmby, M. Snoyek, T. Rhauderwiek, K. Ritter, N. Stock, Cryst. Growth Des. 2014, 14, 5310-5317.

${ }^{25}$ N. Reimer, H. Reinsch, A. Ken Inge, N. Stock, Inorg. Chem. 2015, 54, 492-501.

${ }^{26}$ H. Reinsch, R. S. Pillai, R. Siegel, J. Senker, A. Lieb, G. Maurin, N. Stock, Dalton Trans. 2016, 45, 4179-4186.

${ }^{27}$ M. Sk, S. Bhowal, S. Biswas, Eur. J. Inorg. Chem. 2015, 20, 3317-3322.

${ }^{28}$ H. Reinsch, S. Waitschat, S. M. Chavan, K. P. Lillerud, N. Stock, Eur. J. Inorg. Chem. 2016, 27, 4490-4498.

${ }^{29}$ G. Wißmann, A. Schaate, S. Lilienthal, I. Bremer, A. M. Schneider, P. Behrens, Micropor. Mesopor. Mater. $2012,152,64-70$.

${ }^{30}$ K. A. Brown, D. P. Martin, R. L. LaDuca, CrystEngComm 2008, 10, 1305-1308.

${ }^{31}$ A. Rana, S. K. Jana, S. Datta, R. J. Butcher, E. Zangrando, S. Dalai, J. Solid State Chem. 2013, 207, 61-68.

${ }^{32}$ Y. He, C. Song, Y. Ling, C. Wu, R. Krishna, B. Chen, APL Mater. 2014, 2, 124102.

${ }^{33}$ H. Reinsch, Eur. J. Inorg. Chem. 2016, 27, 4290-4299.

34 J. Wang, K. Zhang, Metab. Eng. 2015, 30, 190-196.

${ }^{35}$ C. Kiener, U. Mueller, M. Schubert, US Patent Application US 2009/0092818 A1, 2009.

${ }^{36}$ S. Biswas, T. Ahnfeldt, N. Stock, Inorg. Chem. 2011, 50, 9518-9526.

${ }^{37}$ A. Comotti, S. Bracco, P. Sozzani, S. Horike, R. Matsuda, J. Chen, M. Takata, Y. Kubota, S. Kitagawa, J. Am. Chem. Soc, 2008, 130, 13664-13672.

${ }^{38}$ C. Volkringer, T. Loiseau, N. Guillou, G. Ferey, M. Haouas, F. Taulelle, E. Elkaim, N. Stock, Inorg. Chem. 2010, 49, $9852-9862$.

39 I. Senkovska, F. Hoffmann, M. Fröba, J. Getzschmann, W. Böhlmann, S. Kaskel, Micropor. Mesopor. Mater. 2009, 122, 93-98.

${ }^{40}$ a) T. Ahnfeldt, N. Guillou, D. Gunzelmann, I. Margiolaki, T. Loiseau, G. Férey, J. Senker, N. Stock, Angew. Chem. Int. Edt. 2009, 48, 5163-5166 ; E. b) Stavitski, M. Goesten, J. Juan-Alcaniz, A. Martinez-Joaristi, P. Serra-Crespo, A. V. Petukhov, J. Gascon, F. Kapteijn , Angew.Chem. Int. Edt. 2011. 50, 9624-9628; C) A. Buragohain, P. Van Der Voort, S. Biswas, Micropor. Mesopor. Mater. 2015, 215, 91-97.

${ }^{41}$ a) Q. Yang, S. Vaesen, M. Vishnuvarthan, F. Ragon, C. Serre, A. Vimont, M. Daturi, G. De Weireld, G, Maurin, J. Mater. Chem. 2012, 22, 10210-10220; b) S. H. Lo, C. H. Chien, Y. L. Lai, C. C. Yang, J. J. Lee, D. S. Raja, C. H. Lin, J. Mater. Chem. A 2013, 1, 324-329.

${ }^{42}$ Materials Studio Version 5.0, Accelrys Inc., San Diego, CA, 2009.

${ }^{43}$ D. Fröhlich, S. K. Henniger, C. Janiak, Dalton Trans. 2014, 43, 15300-15304.

${ }^{44}$ M. F. de Lange, K. J. F. M. Verouden, T. J. H. Vlugt, J. Gascon, F. Kapteijn, Chem. Rev. 2015, 115, 12205-12250.

${ }^{45}$ S. K. Henniger, F. Jeremias, H. Kummer, C. Janiak, Eur. J. Inorg. Chem. 2012, 16, 2625-2634.

${ }^{46}$ H. Kim, S. Yang, S. R. Rao, S. Narayanan, E. A. Kapustin, H. Furukawa, A. S. Umans, O. M. Yaghi, E. N. Wang, Science, 2017, $356,430-434$

${ }^{47}$ F. Meunier, Science, 2017, 358, 6366.

${ }^{48}$ M. F. de Lange, B. L. van Velzen, C. P. Ottevanger, K. J. F. M. Verouden, L.-C. Lin, T. J. H. Vlugt, J. Gascon, F. Kapteijn, Langmuir 2015, 31 , $12783-12796$.

${ }^{49}$ F. Jeremias, D. Fröhlich, C. Janiak, S. K. Henninger, New J. Chem., 2014, 38, 1846-1852.

50 P. Ramaswamy, N. E. Wong, G. K. H. Shimizu, Chem. Soc. Rev. 2014, 43, 5913-5932.

${ }^{51}$ F. Paesani, J. Phys. Chem. C 2013, 117, 19508-19516.

52 G Alberti, M Casciola, L Massinelli, B Bauer, J. Membr. Sci. 2001, 185, 73-81.

${ }^{53}$ D. Marx, ChemPhysChem 2006, 7, 1848-1870.

54 a) D. D. Borges, S. Devautour-Vinot, H. Jobic, J. Ollivier, F. Nouar, R. Semino, T. Devic, C. Serre, F. Paesani, G. Maurin, Angew. Chem. Int. Ed. 2016, 55, 3919-3924; b) P. G. M. Mileo, T. Kundu, R. Semino, V. Benoit, N. Steunou, P. L. Llewellyn, C. Serre, G. Maurin, S. Devautour-Vinot, Chem. Mater. 2017. 29, 7263-7271; c) D. W. Kang, J. H. Song, K. J. Lee, H. G. Lee, J. E. Kim, H. Y. Lee, J. Y. Kim, C. S. Hong, J. Mater. Chem. A, $2017,5,17492-17498$.

55 a) F. Niekiel, M. Ackermann, P. Guerrier, A. Rothkirch, N. Stock, Inorg. Chem. 2013, 52, 8699-8705; b) R. El Osta, M.Frigoli, J.Marrot, M.E. Medina, R.I. Walton, F. Millange, Cryst. Growth Des. 2012, 12, 1531-1537; c) M. Feyand, M. Köppen, G. Friedrichs, N. Stock, Chem. - Eur. J. 2013, 19, 12537-12546; d) Y. Wu, M. I. Breeze, G. J. Clarkson, F. Millange, D. O'Hare, R. I. Walton, Angew. Chem. Int. Ed. 2016, 55, 4992-4996.

${ }^{56}$ a) N. Pienack, W. Bensch, Angew. Chem. Int. Ed. 2011, 50, 2014-2034; b) M. Søndergaard, K. J. Dalgaard, E. D. Bøjesen, K. Wonsyld, S. Dahl, B. B. Iversen, J. Mater. Chem. A 2015, 3, 18667-18674; c) R. J. Francis, S. O’Brien, A. M. Fogg, P. Shiv Halasyamani, D. O'Hare, T. Loiseau, G. Ferey, J. Am. Chem. Soc. 1999, 121, 1002-1015; d) E. Antonova, B. Seidlhofer, J. Wang, M. Hinz, W. Bensch, Chem. Eur. J 2012, 18, 15316-15322.

${ }^{57}$ a) M. Feyand, C. Näther, A. Rothkirch, N. Stock, Inorg. Chem. 2010, 49, 11158-11163; b) H. H.-M. Yeung, Y. Wu, S. Henke, A. K. Cheetham, D. O'Hare, R. I. Walton, Angew. Chem. Int. Ed. 2016, 55, 2012-2016. 
${ }^{58}$ H. Reinsch, J. Benecke, M. Etter, N. Heidenreich, N. Stock, Dalton Trans. 2017, 46, 1397-1405.

59 J. D. Sharp, J. H. Hancock, J. Am. Ceram. Soc. 1972, 55, 74-77.

60 M. Avrami, J. Chem. Phys. 1939, 7, 1103-1112.

${ }^{61}$ A. F. Gualtieri, Phys. Chem. Miner. 2001, 28, 719-728.

62 S. Surble, F. Millange, C. Serre, G. Ferey, R. I. Walton, Chem. Commun. 2006, 1518-1520.

${ }^{63}$ B. Bueken, H. Reinsch, N. Heidenreich, A. Vandekerkhove, F. Vermoortele, C. E. A. Kirschhock, N. Stock, D. De Vos, R. Ameloot, CrystEngComm, 2017, 19, $4152-4156$

64 A. Khawam, D. R. Flanagan, J. Phys. Chem. B 2006, 110, 17315-17328.

65 J. Verduyckt, D. E. De Vos, Chem. Sci. 2017, 8, 2616-2620.

66 Topas Academics 4.2, Coelho Software, 2007.

67 J. Strempfer, S. Francoual, D. Reuther, D. K. Shukla, A. Skaugen, H. Schulte-Schrepping, T. Kracht, H. Franz, J. Synchrotron Radiat. 2013, $20,541-549$.

${ }^{68}$ A. P. Hammersley, S. O. Svensson, M. Hanfland, A. N. Fitch, D. Häusermann, High Pressure Res. 1996, 14, $235-248$.

${ }^{69}$ A. Rothkirch, F3 tool version 0.3k, 2010.

${ }^{70}$ a) K. Barthelet, J. Marrot, G. Férey, D. Riou, Chem. Commun. 2004, 520-521; b) A. Fateeva, P. Horcajada, T. Devic, C. Serre, J. Marrot, J.-M. Grenèche, M. Morcrette, J.-M. Tarascon, G. Maurin, G. Férey, Eur. J. Inorg. Chem. 2010: 24, 3789-3794; c) C. Volkringer, M. Meddouri, T. Loiseau, N. Guillou, J. Marrot, G. Férey, M. Haouas, F. Taulelle, N. Audebrand, M. Latroche, Inorg. Chem. 2008, 47, 11892-11901. 